\title{
PAULO DESTRO
}

\section{O SIGILO MÉDICO PROFISSIONAL NO ÂMBITO DO DIREITO PENAL MÉDICO BRASILEIRO}

\author{
Tese de Doutorado
}

Orientador: Professor Dr. Roberto Augusto de Carvalho Campos

UNIVERSIDADE DE SÃO PAULO

FACULDADE DE DIREITO

São Paulo-SP

2019 


\section{PAULO DESTRO}

\section{O SIGILO MÉDICO PROFISSIONAL NO ÂMBITO DO DIREITO PENAL MÉDICO BRASILEIRO}

Tese apresentada à Banca Examinadora do Programa de Pós-Graduação em Direito da Faculdade de Direito da Universidade de São Paulo, na área de concentração de Direito Penal, Medicina Forense e Criminologia, como exigência parcial à obtenção do título de Doutor em Direito, sob orientação do Prof. Dr. Roberto Augusto de Carvalho Campos.

UNIVERSIDADE DE SÃO PAULO

FACULDADE DE DIREITO

São Paulo-SP 


\section{Catalogação da Publicação}

Destro, Paulo

O sigilo médico profissional no âmbito do direito penal médico brasileiro / Paulo Destro. -- São Paulo: USP / Faculdade de Direito, 2019.

$173 f$.

Orientador: Prof. Dr. Roberto Augusto de Carvalho Campos.

Tese (Doutorado), Universidade de São Paulo, USP, Programa de Pós-Graduação em Direito - área de concentração, Direito Penal, Medicina Forense e Criminologia, 2019.

1. Responsabilidade penal do médico. 2. Confidencialidade 3. Bioética. I. Campos, Roberto Augusto de Carvalho. II. Título. 


\section{FOLHA DE APROVAÇÃO}

Candidato: Paulo Destro

Natureza: Tese de Doutorado

Instituição: Faculdade de Direito da Universidade de São Paulo

Objetivo: Exigência parcial à obtenção do título de Doutor em Direito

Orientador: Professor Doutor Roberto Augusto de Carvalho Campos

Área de Concentração: Direito Penal, Medicina Forense e Criminologia

Data da Banca:

Professor Doutor Roberto Augusto de Carvalho Campos (Orientador)

Professor:

Titulação:

Instituição: Universidade de São Paulo

Professor:

Titulação:

Instituição:

Professor:

Titulação:

Instituição:

Professor:

Titulação:

Instituição:

Professor:

Titulação:

Instituição: 
Aos pais (in memoriam), Hermenegildo Angelo Destro e Mitsuko Yonamine Destro, e a irmã Sandra Destro, a quem tive e tenho a oportunidade de dizer: No desafio de cada conquista, quero deixar passar por mim, a voz sublime e a leveza de suas presenças, renovando o universo interior....

Ao Dr. Antonio Minieri Júnior (in memoriam), médico e amigo de palavras afetuosas, que sabia curar a dor, escutar a alma e dizer: É hora de recomeçar.

À querida Maria Luiza Silveira Piedade, pela amizade. E a Duque e Bob, companheiros de grande alegria e estimação. 


\section{AGRADECIMENTOS}

Ao Mestre Jesus, o intérprete de Deus.

Ao estimado orientador Prof. Dr. Roberto Augusto de Carvalho Campos, exemplo de admiração a ser seguido na carreira docente, pelo apoio e estímulo de sua orientação durante toda a pós-graduação stricto sensu, cujos ensinamentos foram essenciais para o desenvolvimento desta tese.

À Dalva Veramundo Bizerra de Souza, Secretária do Departamento de Direito Penal, pelo constante incentivo.

Aos respeitáveis Professores Doutores Arnaldo Guilherme e Janaína Conceição Paschoal, pelos essenciais apontamentos no exame de qualificação da tese, resultando no aprimoramento desta pesquisa científica.

Aos Professores Doutores Álvaro Villaça Azevedo, Cândido Rangel Dinamarco, Carlos Alberto Dabus Maluf, Luciano Anderson de Souza, Miguel Reale Júnior, Renato de Mello Jorge Silveira e Vicente Greco Filho, cujos ensinamentos nas disciplinas cursadas na pós-graduação stricto sensu contribuem para um melhor desempenho profissional e acadêmico.

À amiga Valderez Deusdedit Abbud (Procuradora de Justiça do Ministério Público do Estado de São Paulo), da qual tive a honra de ser aluno e aprender as primeiras lições de Direito Penal na Faculdade de Direito da Universidade Presbiteriana Mackenzie, e cuja sensibilidade e brilho de suas aulas foram determinantes para o ingresso no Ministério Público Paulista, transmitindo, ainda, a vocação para o estudo permanente do Direito, com palavras que só a minha alma pode compreender.

Ao amigo Marco Vinicio Petrelluzzi (Procurador de Justiça aposentado do Ministério Público do Estado de São Paulo e Advogado), pelo apoio.

Meu coração abraça a todos. 
"Entra em processo com teu próximo, mas não reveles o segredo de outrem"

Provérbios $-25: 9$

"Tem coisas que o coração só fala para quem sabe escutar!" Francisco Cândido Xavier

Segue o teu destino, Rega as tuas plantas, Ama as tuas rosas. O resto é a sombra De árvores alheias.

A realidade

Sempre é mais ou menos

Do que nós queremos.

Só nós somos sempre

Iguais a nós próprios.

Suave é viver só.

Grande e nobre é sempre

Viver simplesmente.

Deixa a dor nas aras

Como ex-voto aos deuses.

Vê de longe a vida.

Nunca a interrogues.

Ela nada pode

Dizer-te. A resposta

Está além dos deuses.

Mas serenamente Imita o Olimpo

No teu coração.

Os deuses são deuses

Porque não se pensam.

1-7-1916

Odes de Ricardo Reis

Fernando Pessoa 
DESTRO, Paulo. O sigilo médico profissional no âmbito do direito penal médico brasileiro. 2019. 173f. Tese (Doutorado). Faculdade de Direito da Universidade de São Paulo, São Paulo, 2019.

\section{RESUMO}

O presente trabalho é produto de uma reflexão, na dogmática penal brasileira, sobre a atual situação do sigilo médico profissional, cuja conduta médica adequa-se na tipificação do crime de violação do segredo profissional, com considerações e críticas no âmbito da bioética, do Direito Penal e bem jurídico e no Direito Processual Penal-Constitucional, envolvendo as questões da intimidade e privacidade. Para o desenvolvimento do estudo do tema, foram expostos e analisados, nos seus aspectos gerais, o Direito Penal Médico, a confidencialidade e a responsabilidade penal médica punível em decorrência da revelação de sigilo médico profissional.

Palavras-chave: Responsabilidade penal do médico - Confidencialidade - Bioética 
DESTRO, Paulo. Professional medical confidentiality under brazilian medical criminal law. 2019. 173p. PhD Thesis, Faculty of Law, University of São Paulo, São Paulo, 2019.

\begin{abstract}
The work herein is the result of a reflection, within Brazilian criminal dogmatics, on the current situation of the professional medical confidentiality, which medical conduct fits in the classification of professional confidentiality violation crime, with considerations and reviews in the fields of bioethics, Criminal Law and legal asset, and in the CriminalConstitutional Procedural Law involving the issues of intimity and privacy. In order to develop the study of the subject herein, the Medical Criminal Law, the confidentiality, and the medical criminal liability punishable as the result of the disclosure of professional medical secrecy were exposed and analyzed in their general aspects.
\end{abstract}

Keywords: Criminal liability of the physician - Confidentiality - Bioethics 
DESTRO, Paulo. Le secret médical professionnel dans le domaine du droit pénal médical brésilien. 2019. 173p. Thèse (Doctorat). Faculté de Droit, Université de São Paulo, 2019.

\section{RÉSUMÉ}

Le présent travail est le résultat d'une réflexion, dans le domaine de la dogmatique juridique brésilienne, concernant la situation actuelle du secret médical, dont la conduite répond à la classification du crime de violation du secret professionnel, avec considérations et critiques dans le domaine de la bioéthique, du Droit Pénal et du bien juridique et dans le cadre du Droit Procédural Pénal-Constitutionnel, en impliquant les questions de la vie privée et de l'intimité. Pour le développement de l'étude sur le thème, ont été exposés et analysés, dans leurs aspects globaux, le Droit Pénal Médical, la confidentialité et la responsabilité pénale médicale punissable en conséquence de violation du secret médical professionnel.

Mots-clés: Responsabilité pénale médicale - Confidentialité - Bioéthique 
DESTRO, Paulo. Il sigilo medico professionista nell'ambito del diritto penale medico brasiliano. 2019. 173p. Tesi (Dottorato). Facoltà di Diritto dell'Università di São Paulo, São Paulo, 2019.

\section{RIASSUNTO}

Il presente lavoro è il risultato di una riflessione, nella dogmatica penale brasiliana, sull'attuale situazione della segretezza medico professionale, la cui condotta medica si adegua nella tipizzazione del delitto di violazione del segreto professionale, con considerazioni e critiche nell'ambito della bioetica, del Diritto Penale e bene giuridico e nel Diritto Processuale Penale-Costituzionale, coinvolgendo i quesiti dell'intimità e privacità. Per lo sviluppo dello studio del tema, sono stati esposti e analizzati, nei loro aspetti generali, il Diritto Penale Medico, la confidenzialità e la responsabilità penale medica punibile nel caso di render noto il sigillo professionale.

Parole chiave: Responsabilità penale del medico - Confidenzialità - Bioetica. 


\section{SUMÁRIO}

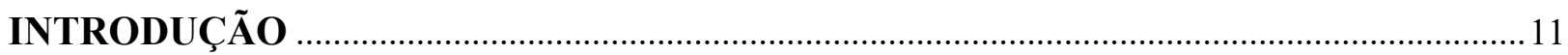

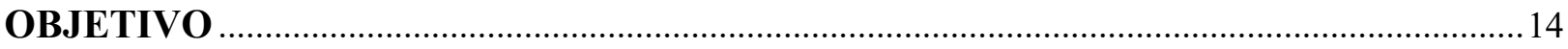

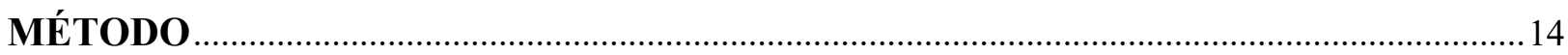

\section{DIREITO PENAL MÉDICO BRASILEIRO: ÂMBITO DE ESTUDO DO SIGILO}

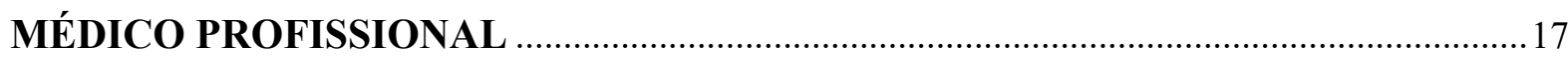

1.1 O princípio ético do segredo médico e sua interação com o Direito Penal............................18

1.2 Segredo e sigilo: conceitos e a experiência jurídico-penal....................................................29

1.3 Bem jurídico penalmente protegido no sigilo médico profissional......................................... 40

1.4 Natureza integrativa, interdisciplinar e hermenêutica.......................................................52

2. CONFIDENCIALIDADE: FUNDAMENTOS DA BIOÉTICA, BIOTECNOLOGIA, GENÉTICA E RELEVÂNCIA NA CIÊNCIA PENAL ...................63

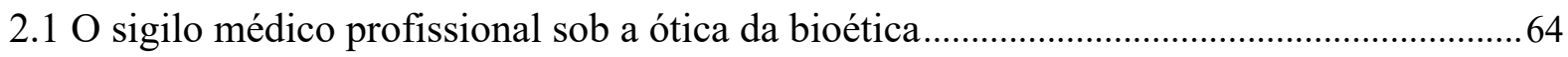

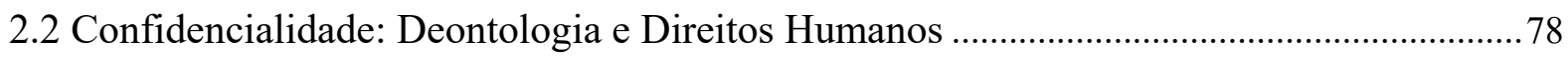

2.3 Confidencialidade e Ciências Penais: Biotecnologia, dados clínicos, biobancos ................ 82

\section{TUTELA CONSTITUCIONAL DA INTIMIDADE E EXTENSÃO DA} CONFIDENCIALIDADE NO DIREITO À PROVA ….....................................................89

3.1 Tutela constitucional da intimidade e direito à privacidade..................................................... 90

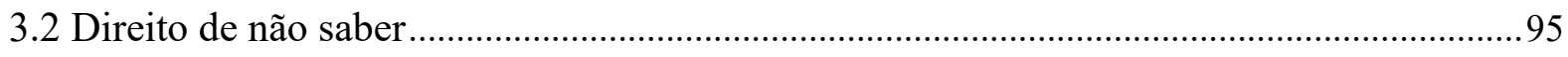

3.3 Direito à prova desvinculado da teoria geral do processo ................................................... 100

3.4 Ministério Público: requisição de prontuário médico e perícias ........................................... 109

\section{RESPONSABILIDADE PENAL EM DECORRÊNCIA DA REVELAÇÃO DE}

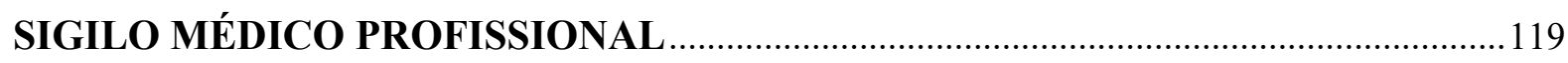

4.1 Fontes jurídicas penais: breve resenha histórica................................................................. 120

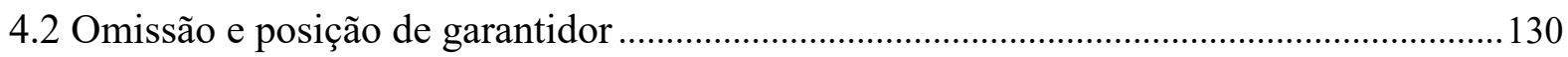

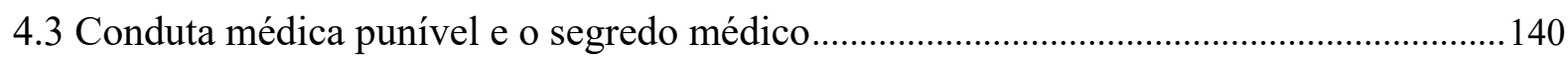

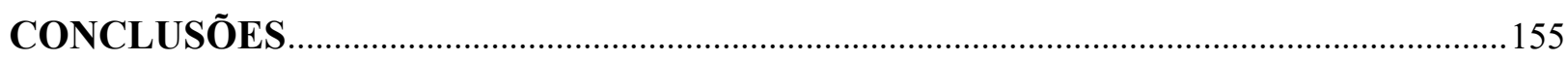

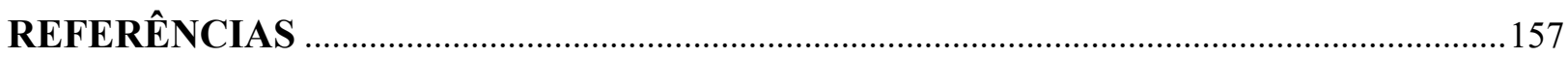




\section{INTRODUÇÃO}

É certo que não há uma expressiva literatura jurídica sobre o sigilo médico profissional no âmbito do Direito Penal Médico brasileiro. Não há, também, estudos e estatísticas do exato número de ações penais, em decorrência da responsabilidade penal médica, no exercício profissional.

É sabido quão importante e relevante é o papel dos médicos na estrutura da sociedade atual, que por estar desequilibrada por situações de massas, geram suas próprias doenças, tornando-se necessária a presença da Medicina, essa arte e ciência de evitar ou curar doença, ou de atenuar seus efeitos.

Apesar da escassa bibliografia específica, a questão do segredo médico e a responsabilidade penal dos médicos decorrente da revelação de sigilo profissional é tão antiga quanto o Direito e a Medicina.

Atualmente, o tema $O$ sigilo médico profissional no âmbito do Direito Penal Médico brasileiro tem despertado enorme interesse.

O Poder Judiciário nacional, em suas várias instâncias, está a todo instante, deparando-se com procedimentos e processos referentes ao presente tema, o que se deve, por um lado, ao aspecto da Medicina de massa e, por outro, a invocação da prestação jurisdicional, para a responsabilização penal dos médicos.

Serve a presente pesquisa para apresentar, inclusive por razões históricas, a importância desse tema e lançar as bases mais relevantes para a sua compreensão axiológica e ética, através de encadeamentos visualizadores. Para atingir os objetivos a que se propõe, a presente tese é composta de quatro capítulos.

No capítulo 1, destacamos no plano da responsabilidade jurídico-penal, na legitimação jurídica da atuação médica e nos interesses de proteção dos pacientes, dentre as novas áreas problemáticas para o Direito Penal Médico Brasileiro, o sigilo médico profissional. Evidenciamos a falta de literatura jurídica sobre os contornos do princípio ético do segredo médico e sua interação com o Direito Penal, a ausência sistemática e de debate no seu cerne de questão, a ser amplamente partilhada em seus aspectos éticos, jurídicos e médicos e, ainda, a necessidade de uma compreensão mais profunda na dogmática penal brasileira. 
Também, neste capítulo, abordamos que a percepção singular e harmônica dos termos segredo e sigilo ou, ainda, segredo médico e sigilo médico profissional constitui-se em terreno fértil e sinuoso para equívocos.

Desenvolvemos, ainda, neste capítulo, a análise perceptiva da construção dogmática do bem jurídico, no campo do Direito Penal Médico Brasileiro, de questões relacionadas com a tutela e responsabilidade penal em decorrência da revelação de sigilo médico profissional.

E, finalizamos o capítulo 1, compreendendo que o estudo do Direito Penal Médico Brasileiro deve ser concebido como verdadeira ciência penal, em uma visão programática, orgânica e unitária, de caráter interdisciplinar, integrativa e hermenêutica, positivada no espaço e no tempo, concretizada na história.

No capítulo 2, da presente pesquisa científica, objetivou-se considerar que o segredo médico e o sigilo médico profissional associam-se ao vasto leque de temas bioéticos, biotecnológicos e genéticos, com consequências relevantes na ciência penal, tutelando-se a confidencialidade a respeito de determinados fatos.

Analisamos, neste aspecto, que as proposições que envolvem a confidencialidade, enfrentadas cotidianamente na prática médica, estão associadas à bioética, termo usado pela primeira vez, em um artigo publicado em 1970, pelo médico americano Van Rensselaer Potter, com o título Bioethics, the science of survival.

Para uma melhor análise conjuntural dessas ponderações, constatou-se que viver em sociedade implica em atos, fatos e outras ocorrências que necessitam ser mantidos em confidencialidade, por razões de proteção individual. Na área da saúde, o segredo médico requer uma proteção maior, correlacionado à deontologia médica e aos postulados éticosmorais que devem ser cumpridos.

No capítulo 3, observamos que o exercício da profissão médica está permeado por elementos éticos-disciplinares abarcando não somente a esfera do Direito Penal, mas outras áreas, como constitucional, civil, administrativo e processual; cuja relevância ultrapassa as relações pessoais, motivando questões de ordem pública e predispondo a normatização.

Neste capítulo, analisamos as discussões doutrinárias envolvendo a intimidade e a vida privada, valores positivados no ordenamento jurídico. 
Analisa-se, ainda, o direito de não saber, vez que a confidencialidade, a privacidade e o sigilo profissional estabelecem valores cuja reflexão não se limita na esfera do sigilo médico profissional.

A ponderação em torno da relevância assumida pelo segredo médico implica na questão do sigilo profissional no âmbito da prova penal, cuja natureza decorre de razões extraprocessuais, delineados pela tutela da intimidade, abrangendo justificativas individuais ou fundamentos coletivos na preservação do sigilo médico profissional.

E, finalizamos o capítulo 3, considerando que, no exercício de suas funções, o Ministério Público poderá requisitar informações, exames periciais e documentos para instruir procedimentos ou processos em que oficie; sendo o membro do Ministério Público responsável pelo uso indevido das informações e documentos que requisitar, inclusive nas hipóteses legais de sigilo.

No capítulo 4, trata-se pormenorizadamente da responsabilidade penal médica, pela imputação a alguém que seja detentor de segredo alheio, de revelação de sigilo médico profissional, com interpretações distintas em diversos ordenamentos jurídicos e sobre o qual a legislação penal brasileira dedicou, do mesmo modo, como objeto jurídico de proteção, o dispositivo elencado no artigo 154, do Código Penal.

Analisam-se, também, as diversas fontes normativas que nos fornecem uma panorâmica acerca da responsabilidade penal decorrente da revelação de sigilo médico profissional.

No panorama doutrinal penalístico brasileiro, patenteia-se escasso o enquadramento dogmático da natureza da omissão e da posição de garante, em relação aos médicos, envolvendo o sigilo médico profissional. Estabelecemos com precisão os conceitos de ação, omissão e de posição de garante, no âmbito da responsabilidade penal médica.

E finalizamos o capítulo 4, analisando os fundamentos do segredo médico, na relação pessoal de confiança na ética clínica, entre médico e paciente, cuja revelação resultava em questionamentos do comportamento médico a ser penalmente responsabilizado. 


\section{OBJETIVO}

O objetivo desta tese é demonstrar no plano da responsabilidade jurídico-penal, na legitimação jurídica da atuação médica e nos interesses de proteção dos pacientes, dentre as novas áreas problemáticas para o Direito Penal Médico Brasileiro, o sigilo médico profissional.

Enfatiza-se o conceito de Direito Penal Médico Brasileiro e, também, nas questões da atuação médica, seja no Brasil ou em outros países, ser usual aos especialistas em Direito e Medicina, pesquisadores e outros profissionais vinculados ao exercício científico da Bioética, uma percepção singular e harmônica dos termos segredo e sigilo ou, ainda, segredo médico e sigilo médico profissional; terreno fértil e sinuoso para equívocos. No âmbito da confidencialidade, o sigilo médico profissional é enfocado sob a ótica da bioética, deontologia e direitos humanos.

Discute-se que o exercício da profissão médica está permeado por elementos éticosdisciplinares abarcando não somente a esfera do Direito Penal mas outras áreas, como constitucional, civil, administrativo e processual; cuja relevância ultrapassa as relações pessoais, motivando questões de ordem pública e predispondo a normatização.

Evidencia-se que Direito e Medicina constituem-se em ciências prudenciais, éticas e propriamente analógicas e nesta conjuntura, a responsabilidade penal em decorrência da revelação de sigilo médico profissional impele a nossa atenção para a necessidade do segredo médico ser compreendido no contexto em que a Medicina é exercida atualmente.

\section{MÉTODO}

A presente tese foi desenvolvida a partir da investigação analítica e dogmática do Direito Penal Médico, âmbito de estudo do sigilo médico profissional, tema pouco avançado na dogmática penal brasileira; mas que inspira pesquisadores no estrangeiro.

O Direito Penal Médico é uma importante área do Direito, que merece estudo e aprofundamento, principalmente no que se refere à responsabilidade penal dos médicos em decorrência da revelação de sigilo médico profissional, diante das controvérsias que lhe são inerentes e que proporcionam debate frutífero sobre as possibilidades e limites desta matéria. 
Em um primeiro momento, são pesquisados os aspectos históricos do princípio ético do segredo médico, justapondo o Direito Penal e a Medicina, numa visão conceitual e, tendo em vista que em sua atividade profissional, o médico se depara com situações nas quais pode ser responsabilizado penalmente em decorrência da revelação de sigilo médico profissional, é necessário o estudo e a compreensão da aplicação de sua natureza integrativa, interdisciplinar e hermenêutica.

A partir da ideia geral desse desenvolvimento, acrescente-se a isso, a concatenação do método dialético no desenvolvimento posterior desta pesquisa, através de livros, alguns raros, aliados as artigos científicos e posições doutrinais modernas e atuais, para a melhor compreensão da confidencialidade sob os fundamentos da bioética, biotecnologia, genética e relevância na ciência penal e, na essência do trabalho, a responsabilidade penal do médico em decorrência da revelação de sigilo médico profissional.

Em razão disso, depreende-se a atualidade e a relevância do objeto de estudo.

Observe-se, ainda, que a pesquisa é de natureza teórico-bibliográfica, seguindo o método descritivo e analítico. A investigação vincula-se, eminentemente, ao Direito Penal brasileiro, de aproximações com ciências afins e, sem prejuízo do trabalho cientifico desenvolvido no panorama internacional. Diante da carência de estudo desta instigante especialidade jurídica, a presente pesquisa visa a contribuição original à ciência jurídica brasileira, com o aprofundamento do estudo do sigilo médico profissional e toda a problemática que o cerca, a partir de temas relativos à responsabilidade penal médica, tendo em vista a legislação, a doutrina e a jurisprudência pertinentes. 


\section{CONCLUSÕES}

1. O Direito Penal Médico Brasileiro é conceituado como o estudo ordenado e sistemático, de natureza interdisciplinar, integrativa e hermenêutica, das normas e princípios éticos, envolvendo questões deontológicas e bioéticas, tutelando bens jurídicos penalmente protegidos, que disciplinam as relações jurídicas constituídas entre a conduta médica punível, os pacientes e as instituições de saúde.

2. No panorama doutrinário brasileiro, sigilo médico profissional (pedra angular do nosso sistema de responsabilidade penal médica) apresenta o seguinte conceito dogmático-penal: é todo fato, ausente de notoriedade e que deve ser preservado, que o médico tenha conhecimento em razão de sua atividade profissional, cuja revelação do segredo a terceiros, total ou parcial, salvo por justa causa ou no cumprimento de dever legal ou com a autorização expressa do paciente, possa acarretar dano a outrem.

3. A importância do segredo médico para a sociedade é antiga, desde sua origem distante, sempre despertou singular interesse à ciência penal, desafiando conceitos fundadores da ética, transpondo diversas interpretações e formas de proteção, no exercício da prática médica. O segredo médico, ínsito nas relações estabelecidas entre o paciente e o médico, no exercício da profissão, da maneira tradicionalmente concebida, constitui-se em garantia, com reflexos em diferentes âmbitos de responsabilização. 


\section{REFERÊNCIAS}

ABBAGNANO, Nicola. Dicionário de filosofia. Tradução de Alfredo Bosi. São Paulo: Ed. Mestre Jou, 1970.

ABREU, Luís Vasconcelos. O segredo médico no direito português vigente. In: Ascensão, José de Oliveira (Coord.). Estudos de direito da bioética. Coimbra: Almedina, 2005.

ACADEMIA NACIONAL DE MEDICINA - ANM. Disponível em: $<$ http://www.anm.org.br>. Acesso em: 25 out. 2017.

AITH, Fernando. O grande segredo: o princípio do segredo médico profissional analisado a partir da decisão da Corte Europeia de Direitos Humanos. Revista de Direito Sanitário, São Paulo, v. 5, n. 2, p. 98-115, jul. 2004. Disponível em: $<$ http://www.revistas.usp.br/rdisan/article/view/80687/84339>. Acesso em 15 maio 2018.

ALAMILLO CANILLAS, Fernando. El secreto médico profesional. Anuario de Derecho Penal y Ciencias Penales, Madrid: n. 3, fasc. 1, jan./abr. 1950.

AlBuQuerque, Paulo Pinto de. Comentário do Código Penal à luz da Constituição da República e da Convenção Europeia dos Direitos do Homem. 3. ed. Lisboa: Universidade Católica Ed., 2015.

ALCALÁ-ZAMORA Y CASTILLO, Niceto. Trayectoria y contenido de una teoría general del proceso. In: ALCALÁ-ZAMORA Y CASTILLO, Niceto. Estudios de teoría general e história del proceso (1945-1972). Cidade do México: Universidad Nacional Autónoma de México, 1974. t. 1.

ALLAMEL-RAFFIN, Catherine; LEPLÈGE, Alain; MARTIRE JUNIOR, Lybio. História da medicina. Tradução de Aquiles Von Zuben. Aparecida-SP: Ed. Ideias \& Letras, 2011.

ALMEIDA, Álvaro Henrique Teixeira de; NIGRE, André Luis (Coords.) Direito e medicina: um estudo interdisciplinar. Rio de Janeiro: Lumen Juris, 2007.

ANDRADE, Andreia da Costa. Os biobancos no atual contexto da investigação científica e preocupações de saúde pública. In: LOUREIRO, João; PEREIRA, André Dias; BARBOSA, Carla (Coords.). Direito da saúde: estudos em homenagem ao Prof. Doutor Guilherme de Oliveira - Saúde e Direito: entre a tradição e a novidade. Coordenadores: João Loureiro, André Dias Pereira e Carla Barbosa. Coimbra: Almedina, 2016. v. 5.

ANDRADE, Manuel da Costa. Comentário Conimbricense do Código Penal. 2. ed. Coimbra: Coimbra Ed., 2012.

Consentimento e acordo em direito penal: contributo para a fundamentação de um paradigma dualista. Coimbra: Coimbra Ed., 2004. 
ANDRADE, Manuel da Costa. Direito penal médico: SIDA: testes arbitrários, confidencialidade e segredo. São Paulo: Revista dos Tribunais; Coimbra: Coimbra Ed., 2008.

AQUINO, José Carlos G. Xavier de. A prova testemunhal no processo penal brasileiro. 6. ed. São Paulo: Letras Jurídicas, 2016.

ARGNANI, Paula Inés. Responsabilidad penal del médico. Buenos Aires: Astrea, 2013.

ASCENSÃO, José de Oliveira. Ensaios clínicos: ponderações ético-jurídicas. In: GOZZO, Débora; LIGIERA, Wilson Ricardo (Orgs.). Bioética e direitos fundamentais. 1. ed. 2. tir. São Paulo: Saraiva, 2014.

ASSEMBLEIA DA REPÚBLICA. Lei n. ${ }^{\circ}$ 59/2007. Diário da República n. ${ }^{\circ}$ 170/2007, Série I de 2007-09-04. Disponível em: <https://dre.pt/pesquisa//search/640142/details/normal?q=59\%2F2007>. Acesso em 13 fev. 2018.

AVECONE, Pio. La responsabilità penale del medico. Padova: Francesco Vallardi, 1981.

BAJO FERNANDES, Miguel. El secreto profesional em el proyecto de Código Penal. Anuario de Derecho Penal y Ciencias Penales, t. 33, fasc./Mês 3, p. 595-610, 1980.

BATISTA, Nilo. Introdução crítica ao direito penal brasileiro. 11. ed. Rio de Janeiro: Ed. Revan, 2007.

BATTAGLINI, Giulio. Direito penal: parte geral. Tradução de Paulo José da Costa Jr, Armida Bergamini Miotto e Ada Pellegrini Grinover. Notas de Euclides Custódio da Silveira. São Paulo: Saraiva; Ed. da Universidade de São Paulo, 1973. v. 1.

BEAUCHAMP, Tom Lamar; CHILDRESS, James Franklin. Princípios de ética biomédica. Tradução de Luciana Pudenzi. 3. ed. São Paulo: Edições Loyola, 2013. Título original Principles of Biomedical Ethics.

BECHARA, Ana Elisa Liberatore Silva. Manipulação genética humana e direito penal. Porto Alegre: Zouk, 2007.

. O rendimento da teoria do bem jurídico no direito penal atual. Revista Liberdades, IBCCRIM, São Paulo, n. 1, p. 16-29, maio/ago. 2009.

BERGSTEIN, Gilberto. A informação na relação médico-paciente. São Paulo: Saraiva, 2013.

BETTIOL, Giuseppe. Direito penal. Campinas: Red Livros, 2000. p. 162.

(Versão portuguesa do original italiano: Diritto penale (parte generale).

BISCAIA, Jorge. Ensaios clínicos em pediatria. In: ASCENSÃO, José de Oliveira (Coord.). Estudos de direito da bioética. Coimbra: Almedina, 2009. v. 3. 
BITENCOURT, Cezar Roberto. Tratado de direito penal: parte especial 2 - Dos crimes contra a pessoa. 12. ed. São Paulo: Saraiva, 2012.

BOTELHO, João Bosco. História da medicina: da abstração à materialidade. Manaus: Ed. Valer, 2004.

BOTSARIS, Alex. Aspectos subjetivos da medicina aplicados ao direito. In: ALMEIDA, Álvaro Henrique Teixeira de; NIGRE, André Luis (Coords.) Direito e medicina: um estudo interdisciplinar. Rio de Janeiro: Lumen Juris, 2007.

BRASIL. Constituição da República Federativa do Brasil de 1988. Disponível em: $<$ http://www.planalto.gov.br/ccivil_03/constituicao/constituicao.htm>. Acesso em 03 mar. 2018 .

. Decreto $n^{o}$ 592, de 6 de julho de 1992. Disponível em: $<$ http://www.planalto.gov.br/ccivil_03/decreto/1990-1994/d0592.htm>. Acesso em 03 mar. 2018.

Lei $n^{\circ} 10.406$, de 10 de janeiro de 2002. Institui o Código Civil. Disponível em: $<$ http://www.planalto.gov.br/ccivil_03/Leis/2002/L10406compilada.htm>. Acesso em 03 mar. 2018.

BRONZE, Fernando José Couto Pinto. A metodonomologia entre a semelhança e a diferença: reflexão problematizante dos pólos da radical matriz analógicado discurso jurídico. Coimbra: Universidade de Coimbra; Coimbra Ed., 1994.

BRUNO, Aníbal. Direito penal: parte geral: pena e medida de segurança. rev. e atual. por Raphael Cirigliano Filho. Rio de Janeiro: Forense, 2009. t. 3.

BURCKHARDT, Jacob. Réflexions sur l'histoire du monde. Version française. Buenos Aires: Janos Peter Kramer, 1943.

BYK, Christian. Tratado de bioética: em prol de uma nova utopia civilizadora? Tradução de Guilherme João de Freitas Teixeira. São Paulo: Paulus, 2015. Título original Traité de bioéthique: vers une nouvelle utopie civilisatrice?

CABRAL, Oswaldo R. O segredo médico em face da lei penal e da deontologia. 1951. Tese (Livre-Docente da Cadeira de Medicina Legal) - Faculdade de Direito de Santa Catarina, Florianópolis, 1951.

CAIRUS, Henrique F.; RIBEIRO JR., Wilson A. Textos hipocráticos: o doente, o médico e a doença. Rio de Janeiro: Ed. FIOCRUZ, 2005. (Coleção história e saúde).

CAMARGO, Antonio Luís Chaves. Imputação objetiva e direito penal brasileiro. 1. ed. 2. tir. São Paulo: Cultural Paulista, 2002. 
CARNEIRO, Antonio Vaz. O sigilo médico versus os imperativos da saúde pública e o dever de cooperação com a justiça. In: ASCENSÃO, José de Oliveira (Coord.). Estudos de direito da bioética. Coimbra: Almedina, 2009. v. 3.

CARNELUTTI, Francesco. Como nasce o direito. Tradução de Roger Vinícius da Silva Costa. São Paulo: Ed. Pillares, 2015.

. O delito. Tradução de Denise Conselheiro. São Paulo: Ed. Rideel, 2007.

CARRARA, Francesco. Programa do curso de direito criminal: parte geral. Tradução de José Luiz V. de A. Franceschini e J. R. Prestes Barra. São Paulo: Saraiva, 1956. v. 1.

. Programa de derecho criminal. Traducción de la 11. ed. italiana dirigida por Sebastián Soler, con la colaboración de Ernesto R. Gavier y Ricardo C. Nuñez. Buenos Aires: Rodamillans, 2010. v. 2.

CARVALHO, Samantha de Araújo. A teoria geral do processo e sua inaplicabilidade no processo penal. Florianópolis: Habitus Ed., 2017.

CASTIGLIONI, Arturo. História da medicina. Tradução de R. Laclette. São Paulo: Companhia Ed. Nacional, 1947. v. 1.

CASTRO, Francisco de. Discursos do Professor Francisco de Castro. Disponível em: $<$ http://www.literaturabrasileira.ufsc.br/documentos/>. Acesso em: 10 out. 2017.

. Discursos do Professor Francisco de Castro. Rio de Janeiro: Typographia Besnard Frères, 1902.

CENEVIVA, Walter. Segredos profissionais. São Paulo: Malheiros Ed., 1996.

CHAIA, Rubén A. Responsabilidad penal médica. Buenos Aires: Hammurabi, 2006.

CINTRA, Antonio Carlos de Araújo; GRINOVER, Ada Pellegrini; DINAMARCO, Cândido Rangel. Teoria geral do processo. 31. ed. São Paulo: Malheiros Ed., 2015.

CÓDIGO PENAL PORTUGUÊS. Disponível em: <http://www.pgdlisboa.pt>. Acesso em: 20 mar. 2018.

COHEN, Claudio. A confidencialidade: questões relativas ao segredo profissional. In: SEGRE, Marco; COHEN, Claudio (Orgs.). Bioética. 3. ed. rev. ampl. São Paulo: Ed. da Universidade de São Paulo, 2008.

; GARCIA, Maria; OLIVEIRA, Reinaldo Ayer de (Orgs.). Estudos e pareceres de bioética. Rio de Janeiro: Elsevier, 2015.

COSTA, Paula Bajer Fernandes Martins da. Ação penal condenatória. 2. ed. São Paulo: Saraiva, 1998. 
COSTA JÚNIOR, Paulo José da. $O$ direito de estar só: tutela penal da intimidade. 4. ed. rev. atual. São Paulo: Revista dos Tribunais, 2007.

COUTINHO, Jacinto N. Miranda. A lide e o conteúdo do processo penal. Curitiba: Juruá, 1989.

CRESPI, Alberto; FORTI, Gabrio; ZUCCALÀ, Giuseppe. Commentario breve al Codice Penale. 13. ed. Padova: Cedam, 2012.

CRUZ E TUCCI, José Rogério. Lições de história do processo civil romano. São Paulo: Revista dos Tribunais, 1996.

DALL'AGNOL, Darlei. Bioética. Rio de Janeiro: Jorge Zahar, 2005.

DE CUPIS, Adriano. Riservatezza e segretto (Diritto a). In: NOVISSIMO digesto italiano. Torino: UTET, 1969.

DESTRO, Paulo. O Ministério Público na defesa da sociedade. In: CONGRESSO DO MINISTÉRIO PÚBLICO DO ESTADO DE SÃO PAULO, 2. Anais... São Paulo: Imprensa Oficial do Estado de São Paulo, 1997.

. O que a sociedade espera do Ministério Público? In: CONGRESSO DO MINISTÉRIO PÚBLICO DO ESTADO DE SÃO PAULO, 3. Anais... São Paulo: Páginas \& Letras Ed. e Gráf., 2006. v. 2.

DIAFÉRIA, Adriana. Direito em um mundo em transformação. In: ZATZ, Mayana. Genética: escolhas que nossos avós não faziam. São Paulo: Globo, 2011.

DIAS, Jorge de Figueiredo. Direito penal: parte geral - questões fundamentais - a doutrina geral do crime. 1 ed. brasileira, 2. ed. port. São Paulo: Revista dos Tribunais; Portugal: Coimbra Ed., 2007. t. 1.

DÍAZ ARANDA, Enrique. El consentimiento en el derecho penal mexicano. Anuario de Derecho Penal y Ciencias Penales, ADPCP, Madrid, v. 49, fasc. 3, p. 1005-1020, 1996.

DIDIER JR., Fredie. Sobre a teoria geral do processo: essa desconhecida. 4. ed. Salvador: Juspodivm, 2017.

DINAMARCO, Cândido Rangel. Fundamentos do processo civil moderno. 2. ed. São Paulo: Revista dos Tribunais, 1987.

A instrumentalidade do processo. 12. ed. São Paulo: Malheiros Ed., 2005.

DINIZ, Carlos Francisco Sica. Privacidade. In: FRANÇA, Rubens Limongi (Org.). Enciclopédia Saraiva de direito. São Paulo: Saraiva, 1981. 
DOTTI, René Ariel. Proteção da vida privada e liberdade de informação. São Paulo: Revista dos Tribunais, 1980.

DURAND, Guy. A bioética: natureza, princípios e objetivos. Tradução de Porphirio Figueira de Aguiar Netto. São Paulo: Paulus, 2005.

. Introdução geral à bioética: história, conceitos e instrumentos. Tradução de Nicolás Nyimi Campanário. 5 ed. São Paulo: Centro Universitário São Camilo: Edições Loyola, 2014.

EBLING, Cláudia Marlise da Silva Alberton. Teoria geral do processo: uma crítica à teoria unitária do processo através da abordagem da questão da sumarização e do tempo/no do processo penal. Porto Alegre: Livr. do Advogado, 2004.

ESER, Albin. Medizin und Strafrecht: Eine schutzgutorientierte Problemübersicht. Zeitschrift für die gesamte Strafrechtswissenschaft (ZStW), 97 Band, Heft 1, p. 1-46, 1985.

- Perspectivas do direito (penal) da medicina. Revista Portuguesa de Ciência Criminal, Coimbra, ano 14, n. 1 e 2, nov. 2004.

ESPÍNOLA FILHO, Eduardo. Código de Processo Penal brasileiro anotado. Atualizadores: José Geraldo da Silva e Wilson Lavorenti. Campinas: Bookseller, 2000.

FACHIN, Luiz Edson. Luzes e sombras no diálogo entre direito e medicina. In: TEIXEIRA, Sálvio de Figueiredo (Coord.). Direito \& medicina: aspectos jurídicos da medicina. Belo Horizonte: Del Rey, 2000.

FARIA, José Eduardo. Paradigma jurídico e senso comum: para uma crítica da dogmática jurídica. In: LIMA, Deodoró Araújo (Org.). Desordem e processo: estudos sobre o direito em homenagem a Roberto Lyra Filho. Porto Alegre: Sérgio A. Fabris Ed., 1986.

FÁVERO, Flamínio. Medicina legal. São Paulo: Livraria Martins Ed., 1974. v. 3.

FAZENDA, Ivani Catarina Arantes. Integração e interdisciplinaridade no ensino brasileiro: efetividade ou ideologia. 6. ed. rev. ampl. São Paulo: Edições Loyola, 2011.

FERRER, Jorge José; ÁlVAREZ, Juan Carlos. Para fundamentar a bioética: teorias e paradigmas teóricos na bioética contemporânea. São Paulo: Edições Loyola, 2005.

FEUERBACH, Paul Johann Anselm Ritter von. Tratado de derecho penal: común vigente en Alemania. Traducción al castellano de la 14. ed. alemana por Eugenio Raúl Zaffaroni e Irma Hagemeier. Buenos Aires: Hammurabi, 2007.

FIOCRUZ. Disponível em: <http://www.dichistoriasaude.coc.fiocruz.br>. Acesso em: 05 set. 2017. 
FRAGOSO, Heleno Cláudio. Lições de direito penal: parte geral. 17. ed. Rio de Janeiro: Forense, 2006.

FRANÇA, Genival Veloso de. Direito médico. 11. ed. Rio de Janeiro: Forense, 2013.

FRANÇA, Rubens Limongi. Hermenêutica jurídica. 13. ed. Atualização de Antônio de S. Limongi França. São Paulo: Revista dos Tribunais, 2015.

2010.

. Princípios gerais de direito. 3. ed. rev. atual. São Paulo: Revista dos Tribunais,

GARCIA, Basileu. Violação de segredo. Revista da Faculdade de Direito da Universidade de São Paulo, São Paulo, v. 44, jan. 1949.

GARCIA, Emerson. Ministério Público: organização, atribuições e regime jurídico. 6. ed. São Paulo: Saraiva, 2017.

GARCÍA GUAL, Carlos. Tratados hipocráticos. Madrid: Editorial Gredos, 1983. v. 1.

GARRAUD, René. Compêndio de direito criminal. Tradução e notas de Ricardo Rodrigues Gama. Campinas/SP: LZN Ed., 2003. v. 1.

GEERDS, F. Einwilligung und Einveständnis des Verletzten im Strafgesetzentwurf, ZStW, 1960.

GILLON, Raanan. Philosofical medical ethics. London: John Wiley \& Sons, 1986.

GIMBERNAT ORDEIG, Enrique. Estudios sobre el delito de omisión. 2. ed. Buenos Aires: B de F, 2013.

GOMES, Benjamim. Ética e medicina: de hipócrates à criação dos primeiros hospitais. Rio de Janeiro: Revinter, 2012.

GOMES, Luiz Flávio; GARCÍA-PABLOS DE MOLINA, Antonio. Direito penal: parte geral. Coordenação Luiz Flávio Gomes. 2. tir. São Paulo: Revista dos Tribunais, 2008. v. 2.

GÓMEZ RIVERO, Maria Del Carmen. La responsabilidad penal del médico. 2. ed. Valencia: Tirant lo blanch, 2008.

GONZAGA, João Bernardino. Violação de segredo profissional. São Paulo: Max Limonad, 1976.

GRACIA, Diego. Fundamentos de bioética. 2. ed. Tradução de Manuel Luís Pinheiro e Vítor Coutinho. Coimbra: Gráfica de Coimbra, 2007. 
GRACIA, Diego. Pensar a bioética: metas e desafios. Tradução de Carlos Alberto Bárbaro. São Paulo: Centro Universitário São Camilo; Edições Loyola, 2010.

GROPPALI, Alessandro. Filosofia del diritto e diritto penale. La Scuola Positiva: rivista di criminologia e diritto criminale, Milano, 1946.

GUERRA FILHO, Willis Santiago. Teoria geral do processo: em que sentido? In: RODRIGUES, Horácio Wanderley (Org.). Lições alternativas de direito processual. São Paulo: Ed. Acadêmica, 1995.

HABERMAS, Jürgen. Consciência moral e agir comunicativo. Tradução de Guido Antonio de Almeida. 2 ed. Rio de Janeiro: Edições Tempo Brasileiro, 2003. (Biblioteca Tempo Universitário; n. 84: estudos alemães). Traduzido do original alemão Moralbewusstsein und kommunikatives Handeln.

HIPÓCRATES. Aforismos. Tradução do Dr. José Dias de Moraes. São Paulo: Martin Claret, 2004.

HIPPOCRATE. De l'art. Hippocrate: oeuvres complètes. Tradução E. Littré. Paris: Javal et Bourdeaux, 1933.

HIPPOCRATES, The art. Hippocrates. Tradução W. H. S. Jones. Cambridge, Havard University Press, 1972. v. 2. (The Loeb Classical Library).

HOTTOIS, Gilbert; MISSA, Jean-Noël. Nova enciclopédia da bioética. Tradução de Maria Carvalho. Lisboa: Instituto Piaget, 2001.

HUNGRIA, Nelson. Comentários ao Código Penal. 4. ed. Rio de Janeiro: Forense, 1958. v. 6.

. Comentários ao Código Penal. Atualizador René Ariel Dotti. 7. ed. Rio de Janeiro: GZ Ed., 2016. v. 1, t. 2.

JÄHNKE, Burkhard. Strafgesetzbuch - Leipziger Kommentar (Großkommentar). 10. völlig neu beabeitete Auflage, 5. Band, Berlin: Walter de Gruyter Co, 1989.

JAKOBS, Günther. Ação e omissão no direito penal. Tradução de Maurício Antonio Ribeiro Lopes. Barueri-SP: Manole, 2003.

. Tratado de direito penal: teoria do injusto penal e culpabilidade. Tradutores: Gercélia Batista de Oliveira Mendes e Geraldo de Carvalho. Belo Horizonte: Del Rey, 2008. Título original Strafrecht. Allgemeiner Teil. Die Grundlagen und die Zurechnungslehre.

JAPIASSU, Hilton. A crise da razão e do saber objetivo: as ondas do irracional. São Paulo: Ed. Letras \& Letras, 1996. 
JAPIASSU, Hilton. Interdisciplinaridade e patologia do saber. Rio de Janeiro: Imago Ed., 1976.

JARDIM, Afrânio Silva. Direito processual penal: estudos e pareceres. 11. ed. Rio de Janeiro: Forense, 2007.

; AMORIM, Pierre Souto Maior Coutinho de. Direito processual penal: estudos e pareceres. 14. ed. Salvador: Juspodivm, 2016.

JESUS, Damásio Evangelista de. Direito penal: parte geral. 25. ed. São Paulo: Saraiva, 2002.

JHERING, Rudolf von. A dogmática jurídica. Tradução de José Ignacio Coelho Mendes Neto. São Paulo: Ícone Editora, 2013. (Coleção fundamentos do direito).

JIMÉNEZ DE ASÚA, Luis. Tratado de derecho penal. 3. ed. Buenos Aires: Editorial Losada, 1957. t. 4.

JONSEN, Albert R.; SIEGLER, Mark; WINSLADE, William J. Ética clínica: abordagem prática para decisões éticas na medicina clínica. 7. ed. Tradução de Ananyr Porto Fajardo. Porto Alegre: AMGH Ed., 2012. Título original Clinical Ethics: a Practical Approach to Ethical Decisions in Clinical Medicine.

KAHN, Alex; LECOURT, Dominique. Bioética e liberdade: entrevista realizada por Christian Godin. Aparecida, SP: Ideias \& Letras, 2007.

KAYSER, Pierre. La protection de la vie privée: protection du secret de la vie privée. Marseille: Presses Universitaires d'Aux-Marseille, 1984.

KRESS, Hartmut. Ética médica. Tradução de Hedda Malina. São Paulo: Edições Loyola, 2008. Título original Medizinische Ethik - Kulturelle Grundlagen und ethische Wertkonflikte heutiger Medizin.

KULLOK, Arthur Levy Brandão. O caso de Andreas Lubitz e o dever de sigilo médico sob a perspectiva do direito penal português. Revista de Estudos Criminais, São Paulo, ano 16, n. 64, p. 53-55, jan./mar. 2017.

LABISCH, Alfons; PAUL, Norbert. Ärtzliche Gelöbnisse. In: KORFF, Wilhelm (Hrsg.). Lexikon der Bioethik, Gütersloh, 1998. v. 1.

LECOURT, Dominique. Erros agradáveis, verdades desagradáveis. In: GOUYON, P.H. et al. A bioética é de má-fé? Tradução de Nicolás Nyimi Campanário. São Paulo: Edições Loyola, 2002. p. 9-14.

Humano pós-humano: a técnica e a vida. Tradução de Luiz Paulo Rouanet. São Paulo: Edições Loyola, 2005. 
LEITE, Alaor. O doping como suposto problema jurídico-penal: um estudo introdutório. In: ROXIN, Claus; GRECO, Luís; LEITE, Alaor. Doping e direito penal. São Paulo: Atlas, 2011.

LESSA, Pedro. Estudos de filosofia do direito. Rio de Janeiro: Tipografia do Jornal do Comércio, Rodrigues \& Cia., 1912.

. Philosophia do direito. Revista da Faculdade de Direito de São Paulo, São Paulo,

v. 4, p. $\quad$ 5-34, $1896 . \quad$ Disponível em:
$<$ https://www.revistas.usp.br/rfdsp/article/view/64925/67537>. Acesso em: 09 fev. 2018.

LEWICKI, Bruno. A privacidade da pessoa humana no ambiente do trabalho. Rio de Janeiro: Renovar, 2003.

LIEBMAN, Enrico Tullio. Recensione - Elio Fazzalari - Istituzioni di diritto processuale. Rivista di Diritto Processuale, Padova, anno 30, n. 3, p. 463-464, 1975.

LIMA, Ruy Cirne. Princípios de direito administrativo. 7. ed. rev. e atual. por Paulo Alberto Pasqualini. São Paulo: Malheiros Ed., 2007.

LLOYD, Geoffrey Ernest Richard. Introduction. In: LLOYD, Geoffrey Ernest Richard. Hippocratic writings. London: Penguin Classics, 1983. p. 9-60.

LOPES JR., Aury. Fundamentos do processo penal: introdução crítica. São Paulo: Saraiva, 2015.

LUNA, Everardo da Cunha. O crime de omissão e a responsabilidade penal por omissão. Revista de Informação Legislativa, Brasília-DF, ano 20, n. 80, out./dez. 1983.

MALUF, Adriana Caldas do Rego Freitas Dabus. A bioética, o biodireito e a biotecnologia na pós-modernidade e os reflexos na alimentação humana. In: SCALQUETTE, Ana Cláudia Silva; CAMILLO, Carlos Eduardo Nicoletti (Coords.). Direito e medicina: novas fronteiras da ciência jurídica. São Paulo: Atlas, 2015.

MARQUES, Manuel Silvério. O espelho declinado: natureza e legitimação do acto médico. Lisboa: Edições Colibri, 1999.

MARTINS-COSTA, Judith; FERNANDES, Márcia Santana. Os biobancos e a doação de material biológico humano: um ensaio de qualificação jurídica. In: GOZZO, Débora; LIGIERA, Wilson Ricardo (Orgs.). Bioética e direitos fundamentais. 1. ed. 2. tir. São Paulo: Saraiva, 2014.

MAURACH, Reinhart. Tratado de derecho penal. Traducción por Juan Cordoba Rode. Barcelona: Ariel, 1962. v. 1.

MAXIMILIANO, Carlos. Hermenêutica e aplicação do direito. 20. ed. Rio de Janeiro: Forense, 2011. 
MEIRELLES, Hely Lopes. Direito administrativo brasileiro. 26. ed. Atualizada por Eurico de Andrade Azevedo, Délcio Balestero Aleixo e José Emmanuel Burle Filho. São Paulo: Malheiros Ed., 2001.

MELLO, Celso Antônio Bandeira de. Curso de direito administrativo. 33. ed. São Paulo: Malheiros Ed., 2017.

MELlo, Oswaldo Aranha Bandeira de. Princípios gerais de direito administrativo. 3 ed. São Paulo: Malheiros Ed., 2010.

MENEZES, Sofia Saraiva de. O direito ao silêncio: a verdade por trás do mito. In: BELEZA, Teresa Pizarro; PINTO, Frederico de Lacerda da Costa (Orgs.). Prova criminal e direito de defesa: estudos sobre teoria da prova e garantias de defesa em processo penal. Lisboa: Almedina, 2010.

MERKL, Adolf. Teoría general del derecho administrativo. México: Ed. Nacional, 1980.

MEZGER, Edmund. Tratado de derecho penal. Traducción al castellano de la 2. ed. alemana por José Arturo Rodríguez Muñoz. Buenos Aires: Hammurabi, 2010.

MICHALOWSKI, Sabine. Medical confidentiality and crime. England: Ashgate Pub, 2003.

MIZIARA, Ivan Dieb; MIZIARA, Carmen Silvia Molleis Galego. Guia de bolso de ética, bioética e deontologia médica. Rio de Janeiro: Ed. Atheneu, 2016.

MONIZ, Helena. Privacidade e comunicação intrafamiliar de informação genética. Revista Portuguesa de Ciência Criminal, Coimbra, ano 14, n. 1 e 2, p. 213-237, 2004.

Segredo médico: acórdão da relação de Coimbra de 5 de julho de 2000. Revista Portuguesa de Ciência Criminal, Coimbra, ano 10, n. 4, p. 631-643, 2004.

MONREAL, Eduardo Novoa. Derecho a la vida privada y liberdad de información. 2. ed. México: Siglo Veintiuno Editores, 1981.

MONTANO, Pedro J. Medicinas alternativas y derecho penal. Buenos Aires: B de F, 2003.

MONTEIRO, Washington de Barros. Curso de direito civil: parte geral. 26 ed. São Paulo: Saraiva, 1986. v. 1.

MORAES, Irany Novah. Erro médico. 2. ed. ampl. São Paulo: Ed. Santos-Maltese, 1991. 2002. Erro médico e a justiça. 5. ed. atual. ampl. São Paulo: Revista dos Tribunais, Longevidade: viver mais e melhor. São Paulo: Ed. Roca, 2004. 
MORAES, Irany Novah; AMATO, Alexandre Campos Moraes. Metodologia da pesquisa cientifica. São Paulo: Ed. Roca, 2007.

MORAES, Maria Celina Bodin de; KONDER, Carlos Nelson. Dilemas de direito civilconstitucional: casos e decisões sobre os novos desafios para a tutela da pessoa humana nas relações existenciais. Rio de Janeiro: Renovar, 2012.

MOREIRA, Rômulo de Andrade. Uma crítica à teoria geral do processo. 2. ed. Salvador: Lex Magister, 2014.

MOSSET ITURRASPE, Jorge; PIEDECASAS, Miguel Alberto. Derechos del paciente: doctrina-jurisprudencia. Santa Fe: Rubinzal-Culzoni Editores, 2011.

NAÇÕES UNIDAS DO BRASIL. Disponível $<$ http://www.onu.org.br/img/2014/09/DUDH.pdf>. Acesso em 03 mar. 2018.

NALINI, José Renato. Ética geral e profissional. 13. ed. rev. atual. e ampl. São Paulo: Editora Revista dos Tribunais, 2016.

A responsabilidade penal do médico. In: TEIXEIRA, Sálvio de Figueiredo Teixeira (Coord.). Direito \& medicina: aspectos jurídicos da medicina. Belo Horizonte: Del Rey, 2000.

NIGRE, André Luis; ALMEIDA, Álvaro Henrique Teixeira de (Orgs.). Direito $e$ medicina: um estudo interdisciplinar. Rio de Janeiro: Lumen Juris, 2007.

NOLL, P. Übergesetzliche Rechtfertigungsgründe im besondern die Einwilligung des Verletzten. Basel, 1955.

NORONHA, Edgard Magalhães. Curso de direito processual penal. 19. ed. atual. por Adalberto José Q. T. de Camargo Aranha. São Paulo: Saraiva, 1989.

. Direito penal. 22. ed. Atualizada por Dirceu de Mello, Eliana Passarelli Lepera. São Paulo: Saraiva, 1987. v. 2.

OLIVEIRA, Antônio Bernardes de. A evolução da medicina: até o início do século XX. São Paulo: Livr. Pioneira Ed.; Secretaria de Estado da Cultura, 1981.

OLIVEIRA, Moacyr de. Intimidade. In: FRANÇA, Rubens Limongi (Org.). Enciclopédia Saraiva de direito. São Paulo: Saraiva, 1980.

ORGANIZAÇÃO DOS ESTADOS AMERICANOS - OEA. Convenção Americana de Direitos Humanos (1969). (Pacto De San José Da Costa Rica). Disponível em: $<$ http://www.pge.sp.gov.br/centrodeestudos/bibliotecavirtual/instrumentos/sanjose.htm>. Acesso em 03 mar. 2018. 
ORGANIZAÇÃO DOS ESTADOS AMERICANOS - OEA. Convenção Europeia de Direitos Humanos. Disponível em: $<$ http://www.oas.org/es/cidh/expresion/showarticle.asp?artID=536\&lID=4>. Acesso em 03 mar. 2018.

ORGANIZACIÓN MUNDIAL DE LA SALUD. Epidemiologia: guia de metodos de enseñanza. Washington, DC, 1973.

PALMEIRA, Sérgio. Direito, medicina e poder: ideologia, artifícios e consequências. São Paulo: Arte Brasil Ed., 2012. v. 1.

PAULO; Luiz Gonçalves; ZANINI, Antonio Carlos. Compliance: sobre o encontro paciente/médico. São Roque, SP: IPEX Ed., 1997.

PEREIRA, André Gonçalo Dias. O dever de sigilo do médico: um roteiro da lei portuguesa. Revista Portuguesa do Dano Corporal, n. 19, p. 9-50, 2009.

PEREIRA, J. Matos. Direito de informação. Lisboa: Associação Portuguesa de Informática, 1980.

PEREIRA, Victor de Sá; LAFAYETTE, Alexandre. Código Penal anotado e comentado: legislação conexa e complementar. 2 ed. Lisboa: Quid Juris, 2014.

PERELMAN, Chaïn. Ética e direito. Tradução de João Duarte. Lisboa: Instituto Piaget, 1990.

PESSINI, Léo. Princípios de ética biomédica. 3. ed. São Paulo: Edições Loyola, 2013.

PIERANGELI, José Henrique. Códigos penais do Brasil: evolução histórica. 2. ed. São Paulo: Revista dos Tribunais, 2004.

. Manual de direito penal brasileiro: parte especial. 2. ed. rev. atual. ampl. e compl. São Paulo: Revista dos Tribunais, 2007.

POTTER, Van Rensselaer. Bioética: ponte para o futuro. Tradução de Diego Carlos Zanella. São Paulo: Edições Loyola, 2016.

RAPOSO, Vera Lúcia. Do ato médico ao problema jurídico. Coimbra: Almedina, 2013.

REALE, Miguel. Filosofia do direito. 20. ed. São Paulo: Saraiva, 2002.

Questões de direito. São Paulo: Sugestões Literárias, 1981.

REALE JÚNIOR, Miguel. Instituições de direito penal: parte geral. 2. ed. 2. tir. Rio de Janeiro: Forense, 2006. v. 1.

Teoria do delito. 2. ed. rev. São Paulo: Revista dos Tribunais, 2000. 
REASON, James. El error humano. Madrid: Modus Laborandi, 2009.

REZENDE, Joffre Marcondes de. À sombra do plátano: crônicas de história da medicina. São Paulo: Ed. Unifesp, 2009.

ROCHA, Arthur Pinto da. O segredo profissional: aspectos jurídicos e médicos. Rio de Janeiro: Calvino Filho Editor, 1935.

RODOTÀ, Stefano. A vida na sociedade da vigilância: a privacidade hoje. Tradução de Danilo Doneda e Luciana Cabral Doneda. Rio de Janeiro: Renovar, 2008.

RODRIGUES, Álvaro da Cunha Gomes. Responsabilidade médica em direito penal: estudo dos pressupostos sistemáticos. Coimbra: Almedina, 2007.

RODRIGUES, João Vaz. O consentimento informado para o acto médico no ordenamento jurídico português: elementos para o estudo da manifestação de vontade do paciente. Coimbra: Coimbra Ed., 2001.

RODRÍGUEZ, Víctor Gabriel de Oliveira. Sigilo médico e direito à privacidade: do delito de desobediência face ao desatendimento de ordem judicial de revelação de dados de pacientes. In: MARTINS, Ives Gandra da Silva; PEREIRA JÚNIOR, Antonio Jorge (Coords.). Direito à privacidade. Aparecida, SP: Ideias \& Letras; São Paulo: Centro de Extensão Universitária, 2005.

RODRÍGUEZ JORDÁN, Marcelo. La responsabilidad penal médica: derechos y obligaciones de las instituciones, funcionarios y profesionales de la salud. Buenos Aires: Legis, 2010.

ROMEO CASABONA, Carlos María. O consentimento informado na relação entre médico e paciente: aspectos jurídicos. In: ROMEO CASABONA, Carlos María; QUEIROZ, Juliane Fernandes (Coords.). Biotecnologia e suas implicações ético-jurídicas. Belo Horizonte: Del Rey, 2004.

- O desenvolvimento do direito diante das biotecnologias. In: ROMEO CASABONA, Carlos María; SÁ, Maria de Fátima Freire de (Coords.). Desafios jurídicos da biotecnologia. Belo Horizonte: Mandamentos Ed., 2007.

. Do gene ao direito: sobre as implicações jurídicas do conhecimento e intervenção no genoma humano. São Paulo: Instituto Brasileiro de Ciências Criminais - IBCCrim, 1999.

. Genética, biotecnologia e ciências penais. Salvador: JusPodivm, 2012.

. Genética y derecho. Buenos Aires: Astrea, 2003.

. El médico y el derecho penal: los problemas penales actuales de la biomedicina.

Santa Fe: Rubinzal-Culzoni Editores, 2011.t. 2, v. 1. 
ROMEO CASABONA, Carlos María. La protección penal del secreto profesional y laboral em derecho español. Revista Brasileira de Ciências Criminais, São Paulo, v. 14, n. 63, p. 76-115, nov./dez., 2006.

; QUEIROZ, Juliane Fernandes (Coords.). Biotecnologia e suas implicações éticojurídicas. Belo Horizonte: Del Rey 2004.

; SÁ, Maria de Fátima Freire de (Coords.). Desafios jurídicos da biotecnologia. Belo Horizonte: Mandamentos Ed. 2007.

ROXIN, Claus. Doping e direito penal. São Paulo: Atlas, 2011.

RUEFF, Maria do Céu. O segredo médico como garantia de não-discriminação: estudo de caso: HIV/SIDA. Coimbra: Coimbra Ed., 2009.

. VIH/Sida, sigilo médico e o modelo de inclusão sem discriminação. In: LOUREIRO, João; PEREIRA, André Dias; BARBOSA, Carla (Coords.). Direito da saúde: estudos em homenagem ao Prof. Doutor Guilherme de Oliveira. Saúde e direito: entre a tradição e a novidade. Coordenadores: João Loureiro, André Dias Pereira e Carla Barbosa. Coimbra: Almedina, 2016. v. 5.

SANTIAGO, Rodrigo. Do crime de violação de segredo profissional no Código Penal de 1982. Coimbra: Almedina, 1992.

SCHÖNKE, Adolf; SCHRÖDER, Horst. Strafgesetzbuch - Kommentar. München: Verlag C. H. Beck, 2006.

SCLIAR, Moacyr. A paixão transformada: história da medicina na literatura. São Paulo: Companhia das Letras, 2005.

SEBAG, Valérie Depadt. Direito e bioética. Tradução de Sandra Campos. Lisboa: Edições Piaget, 2012.

SEGRE, Marco. Considerações críticas sobre os princípios da bioética. In: SEGRE, Marco; COHEN, Claudio (Orgs.). Bioética. 3. ed. rev. ampl. São Paulo: Ed. da Universidade de São Paulo, 2008.

SERRÃO, Daniel. Os desafios contemporâneos da genética. In: ASCENSÃO, José de Oliveira (Coord.). Estudos de direito da bioética. Coimbra: Almedina, 2008. v. 2.

SHECAIRA, Sérgio Salomão. Criminologia. 2. ed. São Paulo: Revista dos Tribunais, 2008.

SIEGHART, Paul. Aids \& human rights: a uk perspective. London: British Medical Association Foundation for Aids, 1989. 
SIEGLER, Mark. Confidentiality in medicine - a decrepit concept. The New England Journal of Medicine, n. 307, p. 1518-1521, Dec., 1982.

SILVA, De Plácido e. Vocabulário jurídico. Atualizadores: Nagib Slaibi Filho e Gláucia Carvalho. 28. ed. Rio de Janeiro: Forense, 2009.

SILVA, João Calvão da. Responsabilidade civil do produtor. Coimbra: Almedina, 1990.

SILVA, José Afonso da. Comentário contextual à Constituição. 9. ed. São Paulo: Malheiros Ed., 2014.

. Curso de direito constitucional positivo. 20. ed. São Paulo: Malheiros Ed., 2002.

SILVA SÁNCHEZ, Jesús-María. Aproximação ao direito penal contemporâneo. Tradução de Roberto Barbosa Alves. São Paulo: Revista dos Tribunais, 2011. (Coleção direito e ciências afins; v. 7. Coordenação: Alice Bianchini; Luiz Flávio Gomes; William Terra de Oliveira).

SILVEIRA, Renato de Mello Jorge. Direito penal supra-individual: interesses difusos. São Paulo: Revista dos Tribunais, 2003.

2010 .

. Fundamentos da adequação social em direito penal. São Paulo: Quartier Latin,

; DINIZ, Eduardo Saad. Autorregulação, responsabilidade empresarial e criminal compliance. In: SILVEIRA, Renato de Mello Jorge; DINIZ, Eduardo Saad. Compliance, direito penal e lei anticorrupção. São Paulo: Saraiva, 2015.

SOLER, Sebastian. Derecho penal argentino. 3. ed. Buenos Aires: Tipografica Ed. Argentina, 1963. v. 1.

SOURNIA, Jean Charles. História da medicina. Tradução de Jorge Domingues Nogueira. Lisboa: Instituto Piaget, 1992.

SOUZA, Fernando Costa e. O futuro da clínica geral. Revista da Ordem dos Médicos, Lisboa, jan. 1992.

SOUZA, Paulo Vinícius Sporleder de. Direito penal médico. Porto Alegre: Livraria do Advogado, 2009.

SPASARI, Mario. L'omissione nella teoria della fattispecie penale. Milano: Giuffrè, 1957.

STRATENWERTH, G. Prinzipien der Rechtfertigung. ZStW, 1965.

TAVARES, Juarez. Direito penal da negligência: uma contribuição à teoria do crime culposo. 2. ed. rev. e ampl. Rio de Janeiro: Lumen Juris, 2003. 
TAVARES, Juarez. Teoria do injusto penal. 3. ed. rev. ampl. Belo Horizonte: Del Rey, 2003.

TELLES JUNIOR, Goffredo. A criação do direito. 3. ed. São Paulo: Saraiva, 2014.

. Ética: do mundo da célula ao mundo dos valores. 3. ed. São Paulo: Saraiva, 2014.

- Palavras do amigo aos estudantes de direito: bosquejos extra-curriculares, proferidos no escritório do Professor, em 2002. 2. ed. São Paulo: Juarez de Oliveira, 2005.

TOLEDO, Francisco de Assis. Princípios básicos de direito penal. 5. ed. 12 tir. São Paulo: Saraiva, 2007.

TORNAGHI, Hélio. Instituições de processo penal. 2. ed. São Paulo: Saraiva, 1978. v. 4.

TUCCI, Rogério Lauria. Considerações acerca da inadmissibilidade de uma teoria geral do processo. Revista Jurídica, Porto Alegre, v. 48, n. 281, p. 48-64, mar. 2001.

; CRUZ E TUCCI, José Rogério. Devido processo legal e tutela jurisdicional. São Paulo: Revista dos Tribunais, 1993.

; PITOMBO, Sérgio Marcos de Moras et al. Princípio e regras orientadoras do novo processo penal brasileiro. Rio de Janeiro: Forense, 1986.

VILLEY, Raymond. Histoire du secret médical. Paris: Éditions Seghers, 1986.

WELZEL, Hans. Derecho penal alemán. Traducción del alemán por Juan Bustos Ramírez y Sergio Yáñez Pérez. Santiago de Chile: Editorial Juridica de Chile, 1997.

ZAFFARONI, Eugenio Raúl; PIERANGELI, José Henrique. Manual de direito penal brasileiro: parte geral. 7. ed. 2 tir. rev. e atual. São Paulo: Revista dos Tribunais, 2008. v. 1.

ZATZ, Mayana. Genética: escolhas que nossos avós não faziam. São Paulo: Globo, 2011. 